\title{
Breathlessness despite optimal pathophysiological treatment: on the relevance of being chronic
}

\author{
To the Editor:
}

In the May 2017 issue of the European Respiratory Journal (ERJ), JoHnson et al. [1] proposed the term "chronic breathlessness syndrome" to describe the clinical situation in which "breathlessness that persists despite optimal treatment of the underlying pathophysiology and results in disability for the patient". The term "disability" in this definition corresponds to "physical limitations and/or a variety of adverse psychosocial, spiritual or other consequences", which very closely matches the World Health Organization definition of the word [2]. The relationship between breathlessness and disability was well captured in the foreword of a document published in 2013 by the Forum of International Respiratory Societies [3], which begins: "When we are healthy, we take our breathing for granted [...]. But when our lung health is impaired, nothing else but our breathing really matters". This has become the "catch phrase" of the French lung health foundation ("Fondation du Souffle", www.lesouffle.org). The explicit definition of "chronic breathlessness" as proposed by JoHnson et al. [1] differs very little from the implicit definition of "refractory breathlessness", the term previously used in many studies, and which was proposed as a distinct entity by some of the authors of a previously published ERJ article [4]. JoHNson et al. [1] submit that defining and naming this new syndrome will improve the visibility of a distressing and debilitating condition that is too often overlooked and neglected [5]. They postulate that this enhanced visibility will result in improved care and organisation of care, stronger research [6], and greater empowerment for patients and their caregivers. The Editorial by BAșoĞLU [7] published in the May 2017 issue of the ERJ throws new light on this notion of empowerment. Making a daring but fascinating parallel between untreated dyspnoea and torture, BAŞOĞLU [7] reminds us how and why addressing dyspnoea in general (and probably "chronic breathlessness" in particular) is a fundamental issue not only from the point of view of medicine per se, but also from the point of view of human rights (on this, see also [8]). He also makes a very convincing case for the importance of empowerment in the management of dyspnoea. Still in the same issue of the ERJ, CALVERLEY [9] comments on the new syndrome and, like us, concurs with JoHnson et al. [1] about the relevance of making breathlessness a foremost concern of every clinician.

In order to contribute to the discussion called for in the article by JoHnson et al. [1], we (a French speaking group of physicians with a special interest in dyspnoea) would like to make a few comments about this article and the accompanying Editorial by CALVERLEY [9]. These comments mostly pertain to the choice of words that has been made to name the new syndrome. In no way should they be interpreted as an expression of disagreement with the proposed approach and its aims; some of the authors of the present letter (C. Morélot-Panzini, D. Adler, E. Allard, C. Chenivesse, P. Laveneziana, L. Laviolette, C. Peiffer and T. Similowski) participated in the "Dyspnea 2016" symposium during which the "chronic breathlessness" discussion was finalised; one of the authors of the article by JoHnson et al. [1] is also a co-author of this letter (T. Similowski). Our letter should be taken as a mere illustration of the fact that differences of opinions always exist within consensus, and also as a substantiation of the dynamic nature of the syndrome-naming process that is put forward by JoHnson et al. [1].

Our first comment concerns using "breathlessness" rather than "dyspnoea" in the name of the syndrome. As "dyspnoea" is widely used in the medical literature and in medical practice, it would be useful to clarify whether "chronic breathlessness syndrome" and "chronic dyspnoea syndrome" can be used interchangeably, and if not, to explain why. This is an important issue, particularly for non-native English

@ERSpublications

Despite maximal pathophysiological treatment, persistent dyspnoea is a distinct entity, be it chronic or acute http://ow.ly/7cR530equaI

Cite this article as: Morélot-Panzini C, Adler D, Aguilaniu B, et al. Breathlessness despite optimal pathophysiological treatment: on the relevance of being chronic. Eur Respir J 2017; 50: 1701159 [https:// doi.org/10.1183/13993003.01159-2017]. 
speakers. The answer to this question can have a significant impact on translations of the name of the new syndrome in other languages.

Our second comment pertains to the use of the term "optimal treatment" in the definition of the syndrome, which can be ambiguous. We understand that, in this context, "optimal" means "maximal", or "state-of-the art", but this may not be exactly the same thing: in some conditions characterised by a marked irreversible component, such as chronic obstructive pulmonary disease (COPD) or pulmonary fibrosis, maximal therapy can fail to provide optimal results both physiologically and, obviously, symptomatically. Beyond semantics, we feel that it is extremely important not to label a patient as suffering from "chronic breathlessness" before being sure that everything has been done to correct the underlying pathophysiological condition, as failure to do so would be associated with a risk of depriving the patient of effective interventions at that time or in the future. For example, if "optimal" treatment of an underlying condition exists but is not available for a given patient at a given time, or if the patient refuses this treatment for any reason, the use of nonspecific symptomatic treatment to alleviate dyspnoea would be valid and in fact essential (as the Editorial by BAşoĞLU [7] clearly reminds us). And yet, the definition of "chronic breathlessness" would not be met, and placing such patients under the "chronic breathlessness" umbrella would carry the risk of forgetting that optimal treatment has not been applied and should be undertaken as soon as it becomes possible.

Our third comment pertains to the choice of the term "syndrome" itself. In his Editorial, Calverley [9] challenges this choice and seems to suggest that "syndrome" should only be used to identify "consistent groups of patients" with a "likely primary condition". Another reason to challenge the term "syndrome" is related to its very definition as "a group of signs and symptoms that occur together and characterise a particular abnormality or condition” (https://www.merriam-webster.com/dictionary/syndrome). This definition is directly derived from the Greek etymology of the word, which means "running together" and thereby implies a combination of items. Since "chronic breathlessness syndrome" apparently comprises only one symptom (dyspnoea), use of the term "syndrome" may be deemed inappropriate. However, the clinical situations covered by "chronic breathlessness syndrome" actually share much more than dyspnoea, as they also have the multiple deleterious consequences of this symptom (e.g. psychological, social, etc.) in common. The term "syndrome" may therefore be very appropriate, particularly to attribute a consistency to otherwise inconsistent groups of patients. This seems to be exactly what has been achieved with "chronic pain syndrome". "Chronic breathlessness syndrome" has the advantage of defining a common basis for the care of patients with a variety of diseases and disorders who are, however, "unified" (as should their caregivers be) by breathlessness, or, more generally, "respiratory suffering". It suggests that all respiratory physicians (and beyond that, all physicians caring for patients with dyspnogenic diseases, and there are many of them) should be familiar with the principles of dyspnoea management in addition to the management of the underlying disease (of note, this is explicitly stated in the 2017 edition of the GOLD statement, which indicates that "all clinicians managing patients with COPD should be aware of the effectiveness of palliative approaches to symptom control and use these in their practice" (see table 4.9 in [10])). Using "symptom" instead of "syndrome" (or omitting "syndrome"), as suggested by CALVERLEY [9], would carry the risk of neglecting the multidimensional and pervasive nature of dyspnoea [11-15]. The process initiated by JoHnson et al. [1] is designed to convince caregivers, and others, that the care of dyspnoea cannot be limited to the treatment of the symptom, but should address its behavioural and socio-psychological consequences. Consequently, we believe that "syndrome" is an appropriate term, as it gives a holistic dimension to the management of dyspnoea.

Our fourth comment, and in fact the most important comment, concerns the term "chronic" in the name of the new syndrome. This choice emerged from a Delphi process, which gives it validity. If one of the goals of creating the new syndrome is to give consistency and visibility to inconsistent and invisible groups of patients (see above), we believe that the word "chronic" could well be counterproductive in a number of cases, as it would deprive many patients of significant conceptual progress. Indeed, all of the concepts used to define "chronic breathlessness" in the article by JoHnson et al. [1] can apply, word for word, to many clinical situations involving acute rather than chronic dyspnoea. For example, all patients hospitalised with severe acute exacerbations of COPD remain dyspnoeic at rest despite oxygen, bronchodilators and corticosteroids, with the corresponding lack of control emphasised by BAŞOĞLU [7] and with shrunken lives. This description exactly fits the definition of the syndrome proposed by JoHNSON et al. [1], with the exception of the time frame. Although this is not standard practice at the moment, these patients could, or more precisely should, be considered for dyspnoea-oriented treatment in addition to pathophysiology-oriented treatment. Even more striking in terms of the temporal dynamics of dyspnoea, is the fact that critically ill patients receiving mechanical ventilation often complain of breathlessness [16]. After dealing with the various technical aspects involved, including optimisation of inappropriate ventilator settings, many of these patients remain breathless [16], a situation strongly suspected to 
contribute to the development of post-traumatic stress syndrome [17]. It will be impossible to convince the intensivists in charge of such patients that they suffer from "chronic breathlessness", even though relief of dyspnoea in this setting is a fundamental clinical mission [18, 19]. We believe that persistence of dyspnoea despite maximal pathophysiological treatment of an acute condition is not a fatality and is not more acceptable than it is in the context of a chronic condition. We therefore also believe that the principles governing the therapeutic approach to acute breathlessness should be exactly the same as the those governing the therapeutic approach to chronic breathlessness. Following are examples of clinical questions that can be formulated to support this contention: "Should noninvasive ventilation be considered in COPD patients during severe acute exacerbations despite complete normalisation of blood gases in response to conventional treatment, in order to alleviate dyspnoea?"; "Should we design trials of short-term, low-dose opioids in addition to pathophysiological treatment in severe exacerbations of COPD?"; "Should we re-think the management of opioids during mechanical ventilation with a dyspnoea paradigm in mind?"; "Should the concept of 'integrated breathlessness service', as developed in supportive care $[20,21]$, be transposed to the intensive care unit?"; "Is there any reason to think that empathy, education and cognitive therapies would not be effective if 'breathlessness that persists despite treatment' is acute rather than chronic"?; and so on. With this in mind, we are afraid that "chronic breathlessness syndrome" could be a misnomer because it would "miss" many "non-chronic" but nonetheless clinically relevant situations. JOHNSON et al. [1] and CALVERLEY [9] briefly refer to this issue, but perhaps do not attribute sufficient importance to what could possibly be seen as a major gap by many practitioners. The name "persistent breathlessness" would have avoided this problem, because it would have covered all acute and chronic situations. "Persistent breathlessness" (or "resistant breathlessness", or any other "time neutral" term) would also have had the advantage of clarifying the discourse in certain cases, possibly with some added teaching value. Let's take an example: "Dear colleague, I am referring this COPD patient to you. She has been treated with dual bronchodilation and inhaled corticosteroids since last year, and presents with chronic breathlessness." It could take quite a long time for this statement to be readily understood by the majority of practitioners. In contrast, "Dear colleague, I am referring this COPD patient to you, who has been treated with dual bronchodilation and inhaled corticosteroids since last year because she complains of persistent breathlessness" can probably more readily understood and is more "teachable" (and "persistent" does not have the negative connotation of "refractory", which for this reason has become "chronic" during the Delphi process elaborated by JoHnson et al. [1]).

All physicians dealing with dyspnoeic patients must have the same objective, namely to alleviate dyspnoea by all means, combining "pathophysiological" and "syndrome-based" strategies, irrespective of the time-frame involved. We suggest that this general goal would be more effectively promoted by the term "persistent breathlessness syndrome" than by "chronic breathlessness syndrome" and we therefore advocate an evolution in this direction. Polling the ERJ readership could perhaps provide useful information on this subject.

Capucine Morélot-Panzini ${ }^{1,2}$, Dan Adler ${ }^{3}$, Bernard Aguilaniu ${ }^{4}$, Etienne Allard ${ }^{5}$, Nathalie Bautin ${ }^{6}$, Marc Beaumont ${ }^{7,8}$, François-Xavier Blanc ${ }^{9}$, Cécile Chenivesse ${ }^{6}$, Laurence Dangers ${ }^{10}$, Christophe Delclaux ${ }^{11,12}$, Alexandre Demoule ${ }^{1,2}$, Philippe Devillier ${ }^{13,14}$, Alain Didier ${ }^{15}$, Marjolaine Georges ${ }^{16}$, Bruno Housset ${ }^{17,18,19}$ Jean-Paul Janssens ${ }^{3}$, Pierantonio Laveneziana ${ }^{1,20}$, Louis Laviolette ${ }^{21}$, Jean-François Muir ${ }^{22}$, Gregory Ninot ${ }^{23}$, Thierry Perez, Claudine Peiffer ${ }^{24}$, Matthieu 'Schmidt ${ }^{25,26}$, Thomas Similowski ${ }^{1,2,19}$, Christian Straus ${ }^{1,20}$, Camille Taillé ${ }^{27,28}$, Sandra Van Den Broecke ${ }^{29}$, Nicolas Roche ${ }^{30,31}$ and the dyspnoea working group of the Société de Pneumologie de Langue Française

${ }^{1}$ Sorbonne Universités, UPMC Université Paris 06, INSERM, UMRS_1158 Neurophysiologie respiratoire expérimentale et clinique, Paris, France. ${ }^{2}$ Assistance Publique-Hôpitaux de Paris (AP-HP), Groupe Hospitalier Pitié-Salpêtrière Charles Foix, Service de Pneumologie et Réanimation Médicale, (Département 'R3S'), Paris, France. ${ }^{3}$ Hôpitaux Universitaires de Genève, Service de Pneumologie, Geneva, Switzerland. ${ }^{4}$ Université Grenoble Alpes, Saint-Martin-d'Hères, France. ${ }^{5}$ Centre hospitalier universitaire Charles Nicolle, Département d'anesthésie-réanimation, Rouen, France. ${ }^{6}$ Centre Hospitalier Universitaire de Lille, Service de Pneumologie et Immuno-Allergologie, Lille, France. ${ }^{7}$ Centre Hospitalier Des Pays de Morlaix, Service de réhabilitation respiratoire, Morlaix, France. ${ }^{8}$ Université de Bretagne occidentale, EA3878, Brest, France. ${ }^{9}$ Centre Hospitalier Universitaire de Nantes, Institut du Thorax, Service de Pneumologie, Nantes, France. ${ }^{10}$ Centre hospitalier universitaire Félix-Guyon, Réanimation polyvalente, Saint-Denis, La Réunion, France. ${ }^{11}$ Assistance Publique-Hôpitaux de Paris (AP-HP), Hôpital Universitaire Robert Debré, Service de Physiologie Explorations Fonctionnelles Pédiatriques-CPPS - Pôle ESPPRII, Paris, France. ${ }^{12}$ Université Paris Diderot, Sorbonne Paris Cité, INSERM U1141, Paris, France. ${ }^{13}$ Université Versailles Saint-Quentin, UFR Sciences de la Santé Simone Veil, UPRES EA 220, Suresnes, France. ${ }^{14}$ Laboratoire de Recherche en Pharmacologie Respiratoire, Hôpital Foch, Suresnes, France. ${ }^{15}$ Centre Hospitalier Universitaire de Toulouse, Hôpital Larrey, Service de Pneumologie, Toulouse, France.

${ }^{16}$ Centre Hospitalier Dijon Bourgogne, Hôpital Francois Mitterrand, Service de Pneumologie et Soins Intensifs Respiratoires, Dijon, France. ${ }^{17}$ Service de pneumologie, Centre hospitalier intercommunal de Créteil, Créteil, France.

${ }^{18}$ Université Paris Est Créteil, Inserm UMRS 955, Créteil, France. ${ }^{19}$ Fondation du souffle, Paris, France. ${ }^{20}$ Assistance Publique-Hôpitaux de Paris (AP-HP), Groupe Hospitalier Pitié-Salpêtrière Charles Foix, Service des Explorations Fonctionnelles de la Respiration, de l'Exercice et de la Dyspnée, (Département 'R3S'), Paris, France. ${ }^{21}$ Centre de recherche, Institut Universitaire de cardiologie et de pneumologie de Québec, Université Laval, Québec, Canada.

${ }^{22}$ Hôpital Charles Nicolle, Service de Pneumologie et Soins Intensifs, Rouen, France. ${ }^{23}$ Université de Montpellier, EA 
4556, Montpellier, France. ${ }^{24}$ Assistance Publique-Hôpitaux de Paris (AP-HP), Hôpital Universitaire Robert Debré, Physiologie Explorations Fonctionnelles, Paris, France. ${ }^{25}$ Sorbonne Universités, UPMC Université Paris 06, iCAN (Institute of Cardiometabolism and Nutrition), Paris, France. ${ }^{26}$ Assistance Publique-Hôpitaux de Paris (AP-HP), Groupe Hospitalier Pitié-Salpêtrière Charles Foix, Service de Réanimation, Paris, France. ${ }^{27}$ Assistance Publique-Hôpitaux de Paris (AP-HP), Hôpital Bichat, Service de Pneumologie et Centre de Compétence des Maladies Pulmonaires Rares, Paris, France. ${ }^{28}$ Université Paris Diderot, INSERM UMR 1152, Paris, France. ${ }^{29}$ Centre Hospitalo-Universitaire St Pierre, Université Libre de Bruxelles, Service de Pneumologie, Brussels, Belgium. ${ }^{30}$ Université Paris Descartes, EA 2511, Paris, France. ${ }^{31}$ Assistance Publique-Hôpitaux de Paris (AP-HP), Groupe Hospitalier Paris Centre site Cochin, Service de Pneumologie et Soins Intensifs Respiratoires, Paris, France.

Correspondence: Capucine Morélot-Panzini, Service de Pneumologie et Réanimation Médicale (Département 'R3S'), Groupe Hospitalier Pitié-Salpêtrière Charles Foix, 47-83 Bd de l'Hôpital, 75651, Paris Cedex 13, France. E-mail: capucine.morelot@psl.aphp.fr

Received: June 92017 | Accepted: June 232017

Conflict of interest: Disclosures can be found alongside this article at erj.ersjournals.com

\section{References}

1 Johnson MJ, Yorke J, Hansen-Flaschen J, et al. Towards an expert consensus to delineate a clinical syndrome of chronic breathlessness. Eur Respir J 2017; 49: 1602277.

2 World Health Organization. World report on disability. http://www.who.int/disabilities/world_report/2011/en/ Date last updated: December 2016. Date last accessed: June 2017.

3 Forum of International Respiratory Societies. Respiratory diseases in the world: realities of today, opportunities for tomorrow. https://www.ersnet.org/pdf/publications/firs-world-report.pdf Date last accessed: June 2017. Date last updated: 2013.

4 Johnson MJ, Currow DC. Chronic refractory breathlessness is a distinct clinical syndrome. Curr Opin Support Palliat Care 2015; 9: 203-205.

5 Gysels M, Higginson IJ. Access to services for patients with chronic obstructive pulmonary disease: the invisibility of breathlessness. J Pain Symptom Manage 2008; 36: 451-460.

6 Currow DC, Abernethy AP, Allcroft P, et al. The need to research refractory breathlessness. Eur Respir J 2016; 47: 342-343.

7 Başoğlu M. Effective management of breathlessness: a review of potential human rights issues. Eur Respir J 2017; 49: 1602099 .

8 Currow DC, Abernethy AP, Ko DN. The active identification and management of chronic refractory breathlessness is a human right. Thorax 2014; 69: 393-394.

9 Calverley PMA. Chronic breathlessness: symptom or syndrome? Eur Respir J 2017; 49: 1700366

10 Global Strategy for Diagnosis, Management and Prevention of COPD. Global Initiative for Chronic Obstructive Lung Disease (GOLD), 2017 final report. http://goldcopd.org/gold-reports/ Date last accessed: June 2017. Date last updated: March 2017.

11 Laviolette L, Laveneziana P. Dyspnoea: a multidimensional and multidisciplinary approach. Eur Respir J 2014; 43: $1750-1762$.

12 Parshall MB, Schwartzstein RM, Adams L, et al. An official American Thoracic Society statement: update on the mechanisms, assessment, and management of dyspnea. Am J Respir Crit Care Med 2012; 185: 435-452.

13 Banzett RB, O'Donnell CR, Guilfoyle TE, et al. Multidimensional Dyspnea Profile: an instrument for clinical and laboratory research. Eur Respir J 2015; 45: 1681-1691.

14 Morélot-Panzini C, Gilet H, Aguilaniu B, et al. Real-life assessment of the multidimensional nature of dyspnoea in COPD outpatients. Eur Respir J 2016; 47: 1668-1679.

15 Williams MT, John D, Frith P. Comparison of the Dyspnoea-12 and Multidimensional Dyspnoea Profile in people with COPD. Eur Respir J 2017; 49: 1600773.

16 Schmidt M, Demoule A, Polito A, et al. Dyspnea in mechanically ventilated critically ill patients. Crit Care Med 2011; 39: 2059-2065.

17 de Miranda S, Pochard F, Chaize M, et al. Postintensive care unit psychological burden in patients with chronic obstructive pulmonary disease and informal caregivers: a multicenter study. Crit Care Med 2011; 39: 112-118.

18 Chanques G, Nelson J, Puntillo K. Five patient symptoms that you should evaluate every day. Intensive Care Med 2015; 41: 1347-1350.

19 Schmidt M, Banzett RB, Raux M, et al. Unrecognized suffering in the ICU: addressing dyspnea in mechanically ventilated patients. Intensive Care Med 2014; 40: 1-10.

20 Booth S, Ryan R, Spathis A. Service delivery of complex interventions for refractory breathlessness. Curr Opin Support Palliat Care 2016; 10: 228-235.

21 Higginson IJ, Bausewein C, Reilly CC, et al. An integrated palliative and respiratory care service for patients with advanced disease and refractory breathlessness: a randomised controlled trial. Lancet Respir Med 2014; 2: 979-987. 
From the authors:

With regard to the letter from Morélot-Panzini and colleagues in response to our Perspective [1], it is good to see support for the concept of a clinical syndrome and its potential in raising awareness of the needs of such patients in the minds of all clinicians; we welcome the ongoing discussion. It serves to highlight the importance of this neglected patient group and clinical topic, as well as the process for how an internationally agreed name and definition in English can be translated both linguistically and culturally in non-English-speaking countries. This letter highlights the thought processes that will need to occur in each translation of the concept. In seeing this work already occurring, our Perspective [1] has already achieved one of its aims.

The comments in the letter mainly relate to these specific linguistic and cultural interpretations, whilst a few relate to the issue of the international name and definition. Taking each point in turn:

"Refractory". Using the Delphi process described in the Perspective [1], candidate words already in use as well as those proposed de novo by members of the panel were considered. "Refractory" was one of several potential words considered. An earlier opinion piece was an integral part of the evolution of the concept of the syndrome [2]. The ultimate output of the Delphi process reflected the consensus of over 30 experts (see table S1 in [1])

"Breathlessness" or "dyspnoea". The discussion regarding this has already been described in detail in the Perspective piece [1]. The consensus relates to the internationally recognised name of the syndrome in English. The consensus was that the term should be that used by the lay public rather than healthcare professionals. Professionals will understand both, whereas the lay public may not understand "dyspnoea", as one of the aims of a syndrome is to empower patients and their families to bring this concern to clinical notice. At least in English, "breathlessness" and "dyspnoea" are not interchangeable. For there to be a cultural and linguistic translation to languages other than English, it should be a term used by their lay public.

"Optimal treatment". After much discussion during the consensus process and workshop, the term "optimal" used in the Perspective referred to the available, tolerated and patient-accepted evidence-based intervention(s) targeting the primary pathophysiological processes of the underlying disease [1]. This is not sufficiently clear in the Perspective piece, although touched on in table S1 [1]. There is no intention that patients should be deprived of interventions targeted at the symptomatic management of their breathlessness because they do not tolerate, refuse or cannot access state of the art treatment for their medical condition. On the contrary, one of the aims of defining such a clinical syndrome is to draw attention to the available breathlessness-targeted treatments. These should be used systematically alongside disease-directed treatments both whilst disease treatments are being optimised and thereafter. This also mandates the review of how breathlessness is being managed regularly in order to gain the best possible outcomes for patients and their families. For people with chronic breathlessness syndrome, attention to the need for and use of breathlessness-targeted treatment will still be reviewed regularly with each clinical encounter.

Syndrome. We agree with the points made in response to the editorial by CALVERLEY [3] regarding the appropriateness of a syndrome relating to a single symptom. In addition, albeit one symptom, breathlessness is made up of a number of "qualitatively distinct sensations" as a result of the multidimensional nature of the patient experience.

Application and relevance to acute care medicine. As described in our Perspective [1], experts were specifically chosen because of their recognised skills from a range of clinical and laboratory backgrounds to ensure that the consensus took account of a broad range of opinion and experience (34 Delphi panel members). A significant number of acute care physicians were included although, as the surveys were

@ERSpublications

Chronic breathlessness syndrome, an international name, should be translated for non-Englishspeaking countries http://ow.ly/vvFT30erPmC

Cite this article as: Johnson MJ, Yorke J, Hansen-Flaschen J, et al. Breathlessness despite optimal pathophysiological treatment: on the relevance of being chronic. Eur Respir J 2017; 50: 1701297 [https:// doi.org/10.1183/13993003.01297-2017]. 
anonymous (a key part of Delphi methodology so any one individual or group is less likely to influence the views of others), this would have been unknown to other survey members. Out of the 34 respondents in the first survey, at least 10 were senior physicians in acute specialties (general medicine, respiratory medicine, cardiology, care of the elderly, anaesthetics). Two authors on the Perspective paper have particular experience in acute and critical care. This subject was therefore assessed in some depth as part of the consensus process.

The context of disability was carefully chosen to distinguish that chronic breathlessness syndrome did not refer to acute breathlessness but rather to people experiencing breathlessness, with its consequent limitations, in their everyday lives. It highlighted that interventions are needed to remove the environmental and social barriers faced by people living with these disabilities [4]. The recently described "dyspnoea crisis" [5] was referred to in our Perspective to highlight that these two clinical aspects of breathlessness are distinct entities even though both relate to the person living with chronic breathlessness. This aspect has been picked up and further reinforced by an article recently published in the Annals of the American Thoracic Society [6]. The consensus panel felt that a stated time-frame was not needed to make this clear as there was a common understanding of the term in English and in medical parlance. However, that might need to be made more explicit, especially for those from non-English-speaking countries.

The term "chronic" was also felt to be useful in signalling "abnormal" breathlessness, distinct from the breathlessness experienced in health in appropriate response to both physical and emotional exertion. In addition, as previously discussed (in the section on optimal treatment), this syndrome does not preclude symptom management of breathlessness caused by acute insults, such as pneumonia and bronchoconstriction, which are expected to improve rapidly with treatment. Separate work is needed in order to learn how best to assess and treat the symptom of acute breathlessness in this situation, but this goes beyond the syndrome described in our Perspective [1].

We agree that it would be helpful to further define "optimal" as "available, tolerated and patient-accepted evidence-based intervention(s)" and to clarify that the "syndrome" refers to chronic as distinct from acute breathlessness. We conclude that the name "chronic breathlessness syndrome" should remain the internationally used English term, and reiterate that this will need to be translated according to other language and cultures, using the word(s) employed by the lay public when they visit their family physician, cardiologist or pulmonologist.

Miriam J. Johnson ${ }^{1}$, Janelle Yorke ${ }^{2}$, John Hansen-Flaschen $\oplus^{3}$, Robert Lansing ${ }^{4}$, Magnus Ekström ${ }^{5}$ and David C. Currow ${ }^{1,6}$

${ }^{1}$ Wolfson Palliative Care Research Centre, Hull York Medical School, University of Hull, Hull, UK. ${ }^{2}$ School of Nursing, Midwifery and Social Work, University of Manchester, Manchester, UK. ${ }^{3}$ Perelman School of Medicine, Hospital of the University of Pennsylvania, Philadelphia, PA, USA. ${ }^{4}$ Beth Israel Hospital Harvard Medical School, Boston, MA, USA. ${ }^{5}$ Dept of Clinical Sciences, Division of Respiratory Medicine \& Allergology, Lund University, Lund, Sweden. ${ }^{6}$ Faculty of Health, University of Technology Sydney, Sydney, Australia.

Correspondence: Miriam J. Johnson, Allam Medical Building, Hull York Medical School, University of Hull, Hull, HU6 7RX, UK. E-mail: miriam.johnson@hyms.ac.uk

Received: June 282017 | Accepted: July 172017

Conflict of interest: Disclosures can be found alongside this article at erj.ersjournals.com

\section{Reference}

1 Johnson MJ, Yorke J, Hansen-Flaschen J, et al. Towards an expert consensus to delineate a clinical syndrome of chronic breathlessness. Eur Respir J 2017; 49: 1602277.

2 Johnson MJ, Currow DC. Chronic refractory breathlessness is a distinct clinical syndrome. Curr Opin Support Palliat Care 2015; 9: 203-205.

3 Calverley PMA. Chronic breathlessness: symptom or syndrome? Eur Respir J 2017; 49: 1700366.

4 World Health Organization. International Classification of Functioning, Disability and Health (ICF): Towards a Common Language for Functioning, Disability and Health. http://www.who.int/classifications/icf/icfbeginnersguide. pdf Date last accessed: August 24 2017. Date last updated: 2002.

5 Mularski RA, Reinke LF, Carrieri-Kohlman V, et al. An official American Thoracic Society workshop report: assessment and palliative management of dyspnea crisis. Ann Am Thorac Soc 2013; 10: S98-S106.

6 Mularski RA. Advancing a common understanding and approach to dyspnea management. Consensus proposal for the chronic breathlessness syndrome. Ann Am Thorac Soc 2017; 14: 1108-1110. 
From the author:

Morélot-Panzini and colleagues response to the paper by JoHnson et al. [1] is an important contribution to the debate about the chronic breathlessness syndrome, which I called for in my editorial [2] and to which others have already contributed [3,4]. English is a greedy language using words that mean the same in their original tongue to denote slight differences in meaning in English. In this case, dyspnoea is the technical term for breathlessness. In 40 years of clinical practice I never met a patient who complained of dyspnoea but saw many who were greatly affected by what they called breathlessness. This distinction between the symptom and its impact are at the heart of the discussions around the chronic breathlessness syndrome. I strongly support the need to provide more holistic care that looks at the consequences of breathlessness as well as their causes. However, important secondary effects on mood, behaviour and lifestyle occur in many chronic conditions not fully controlled by medical-management strategies. Should we refer to chronic arthritis syndrome or chronic cluster headache syndrome or any of the numerous other examples which readily suggest themselves? Whether or not we use the word syndrome these patients need better care than they currently receive.

Morélot-Panzini and colleagues make a cogent case for substituting the word "persistent" for "chronic" as it fits better with the problems they have identified in acute care. However, we should be cautious about making one term suit the needs of all circumstances. The clinical and societal impact of breathlessness is likely to be quite different for the patient in the intensive care unit needing ventilatory support after an acute illness and the patient with idiopathic hyperventilation who is an ambulatory outpatient. Making "one size fit all" will be a difficult task.

The major challenge ahead is not just to select the correct words (semantic arguments are of great interest to specialists but seldom advance the cause of patients) but instead to decide on the needs of patients with breathlessness and how best to meet them. If we focus on doing this then I suspect we will find the most appropriate words to describe those we are trying to help.

@ERSpublications

Chronic breathlessness is an under-recognised problem irrespective of the terminology used to describe it http://ow.ly/kKQs30es6A8

Cite this article as: Calverley PMA. Breathlessness despite optimal pathophysiological treatment: on the relevance of being chronic. Eur Respir J 2017; 50: 1701376 [https://doi.org/10.1183/13993003.01376-2017].

Peter M.A. Calverley

Clinical Science, University Hospital Aintree, Liverpool, UK.

Correspondence: Peter M.A. Calverley, Clinical Science, University Hospital Aintree, Liverpool, UK.

E-mail: pmacal@liverpool.ac.uk

Received: July 92017 | Accepted: July 102017

Conflict of interest: None declared.

\section{References}

1 Johnson MJ, Yorke J, Hansen-Flaschen J, et al. Towards an expert consensus to delineate a clinical syndrome of chronic breathlessness. Eur Respir J 2017; 49: 1602277.

2 Calverley PMA. Chronic breathlessness: symptom or syndrome? Eur Respir J 2017; 49: 1700366.

3 Başoğlu M. Effective management of breathlessness: a review of potential human rights issues. Eur Respir J 2017; 49: 1602099

4 Mularski RA. Advancing a common understanding and approach to dyspnea management. Consensus proposal for the chronic breathlessness syndrome. Ann Am Thorac Soc 2017; 14: 1108-1110. 